\title{
VISCOSITY ANALYSIS OF EMPTY FRUIT BUNCH (EFB) BIO-OIL
}

\author{
Z.S. Nazirah ${ }^{1}{ }^{*}$, M.J.M. Ridzuan ${ }^{1}$, S.M. Hafis ${ }^{1}$, A. R.Mohamed ${ }^{2}$ and K.Azduwin ${ }^{2}$ \\ ${ }^{1}$ Mechanical Engineering Programme, \\ School of Mechatronics Engineering, \\ Universiti Malaysia Perlis \\ 02600 Pauh Putra, Perlis, Malaysia \\ *Email: sitinazirah.zamri@ymail.com \\ Phone: +6049885246; Fax: +6049885167 \\ ${ }^{2}$ School of Bioprocess Engineering, Universiti Malaysia Perlis \\ 02600 Arau, Perlis, Malaysia
}

\begin{abstract}
Empty fruit bunches (EFB) are one of the solid wastes produced by the palm oil industry, which is increasing rapidly. The aim of this paper is to analyse the viscosity of empty fruit bunch (EFB) bio-oil that can be extracted from all solid waste EFB as a sample, and a few processes were executed. The samples underwent two processes, which were pre-treatment and pyrolysis. The pre-treatment involved three processes, namely, cutting, shredding and sieving, which were necessary in order to prepare EFB into a particle size suitable for the reactor. After that, the samples were fed into the feedback reactor as feedstock for the pyrolysis process to produce bio-oil. Once the biooil was produced, its viscosity was tested using the Brookfield Viscometer in two conditions: before and after the chemical reaction. The bio-oil was treated by adding 10 $\mathrm{ml}$ and $20 \mathrm{ml}$ of acetone respectively through the chemical reaction. The viscosity test was carried out at different temperatures, which were $25^{\circ} \mathrm{C}, 30^{\circ} \mathrm{C}, 35^{\circ} \mathrm{C}, 40^{\circ} \mathrm{C}, 45^{\circ} \mathrm{C}$ and $50^{\circ} \mathrm{C}$ respectively. The observed viscosity of the $\mathrm{EFB}$ bio-oil varied and was higher as the temperature decreased. In addition, the viscosity of the EFB bio-oil was higher when it reacted chemically with the acetone added. Therefore, the results showed that the chemical reaction with acetone has the potential to increase the viscosity of EFB bio-oil.
\end{abstract}

Keywords: Empty fruit bunch; bio-oil; pyrolysis; viscosity.

\section{INTRODUCTION}

Currently Malaysia is the largest exporter of palm oil in the international market. About 7.3 million tons of EFB are generated annually (Gawrilow, 2003). In the process of extracting oil, biomass materials such as palm empty fruit bunches (EFB) are generated as waste products. Oil palm (Elaeis guianensis) originated from Africa, and it grows well in wet and humid places like Malaysia (Hassan, Ishida, Shukri, \& Tajuddin, 1994). As generally known, palm oil is a vegetable oil which is biodegradable. Palm trees have a high yield of oil production, which may be able to fulfil the demand for vegetablebased lubricating oil in the future. From other sources, too, bio-oil also promises to serve as an alternative source of energy and can be used as a substitute for conventional fuels after being upgraded (Yiin, 2013). One hectare of palm trees can produce almost 10 times the volume of oil of other sources of vegetable oil (Syahrullail, Zubil, Azwadi, \& Ridzuan, 2011). EFB is one of the biomass materials that is generated as a waste 
product; it is potentially a major source of renewable energy. Hence, it would be beneficial to study the characteristics of EFB so that this bio-waste can be put to good use. In order to produce oil from EFB, we need to know the properties of the biomass, such as the most suitable size of sample for the optimum rate of oil production to be achieved.

Based on the sample size study of previous study, it was found that an increase in particle size from $53-6 \mathrm{~mm}$ to $270-500 \mathrm{~mm}$ led to a decrease in the maximum tar yield from $53 \%$ to $38 \%$ (mass \% of parent fuel). In fluidized bed experiments at $500^{\circ} \mathrm{C}$, the effect of particle size on the secondary conversion of tars was also suspected during the pyrolysis of fine fuel particles $(3-12 \mathrm{~mm})$. The maximum bio-oil yield (58wt\% of biomass feed) was obtained at a reaction temperature of $500^{\circ} \mathrm{C}$ with a particle size of $212-425 \mathrm{~mm}$. The smaller the desired size of biomass particles, the more expensive the feedstock preparation costs are. To put this in perspective, a previous study showed that reducing biomass to particles in the size range of $2.5 \mathrm{~mm}$ to $250 \mathrm{~mm}$ would increase the costs in the range of $\$ 1.80 /$ ton to $\$ 5.60 /$ ton. In the early days of pyrolysis development, researchers thought that particle sizes of a few hundred microns were needed to facilitate high heat transfer rates. However, more recent practical experience has demonstrated that this is not the case, but sizes of approximately $2 \mathrm{~mm}$ are still necessary. The particle size influences the mass fraction and average ash of EFB, as presented by (Abdullah \& Gerhauser, 2008) and (Abdullah, 2005). As is well known, feedstock with a high value of ash, and in particular potassium, leads to reduced liquid yields in fast pyrolysis. In other contexts, the high ash content of the original straw tends to promote chars that form reactions during pyrolysis. Moreover, these are typical observations made from fast pyrolysis of agricultural residues or energetic crops such as switch grass, which are all characterized by high ash contents (Isahak, Hisham, Yarmo, \& Yun Hin, 2012).

\section{EXPERIMENTAL PROCEDURE}

\section{Materials}

Seasoned EFB aged more than 6 months, washed with tap water, and dried at room temperature under moving air for a minimum of 1 week, was used in this research. Prior to the production of empty fruit bunch (EFB) bio-oil, a number of processes had to be carried out.

\section{Pre-treatment of EFB}

Figure 1 shows the EFB sample before undergoing the pre-treatment process. This sample comes in bunches and needs to be processed in order to obtain suitable sizes. The EFB sample for this experiment needed to be cut manually into certain particle sizes using scissors. After that, the biomass was shredded into fine particles using a shredder machine, as shown in Figure 2. The purpose of reducing the particle size was to increase the surface area for catalytic reaction and to reduce the feedstock size to $>1$ $\mathrm{mm}$. After the shredding process, the biomass was sieved according to a particle size range shown in Figure 3; altogether there were five particle sizes in the range, which were $>1 \mathrm{~mm}, 710-1000 \mu \mathrm{m}, 500-710 \mu \mathrm{m}, 250-500 \mu \mathrm{m}$, and $<250 \mu \mathrm{m}$. Based on several extensive process trials of producing bio-oil in a reactor, it was found that particles 
between the sizes of 710-1000 $\mu \mathrm{m}$ produced more oil than particles of other sizes. Therefore, the ideal particle size of feedstock for this study was 710-1000 $\mu \mathrm{m}$.

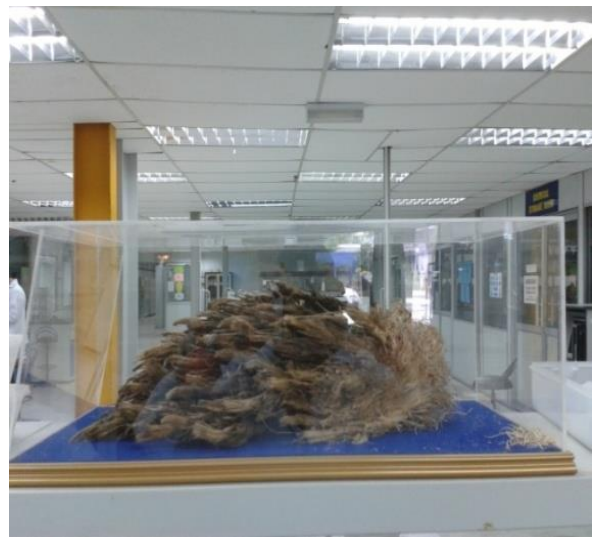

(a)

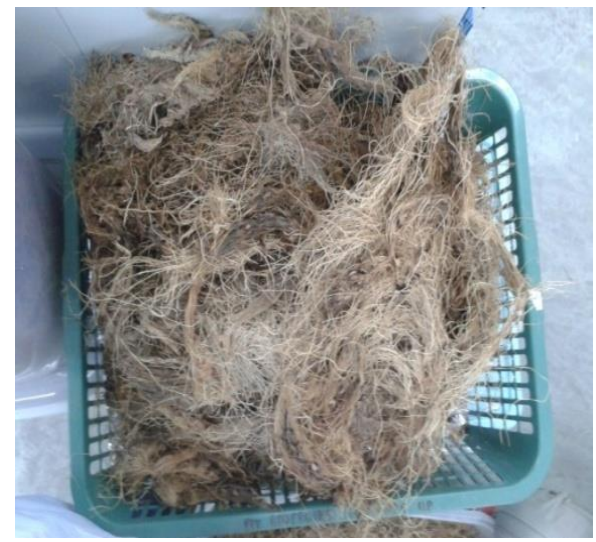

(b)

Figure 1. The EFB sample: (a) before cutting; (b) after cutting.

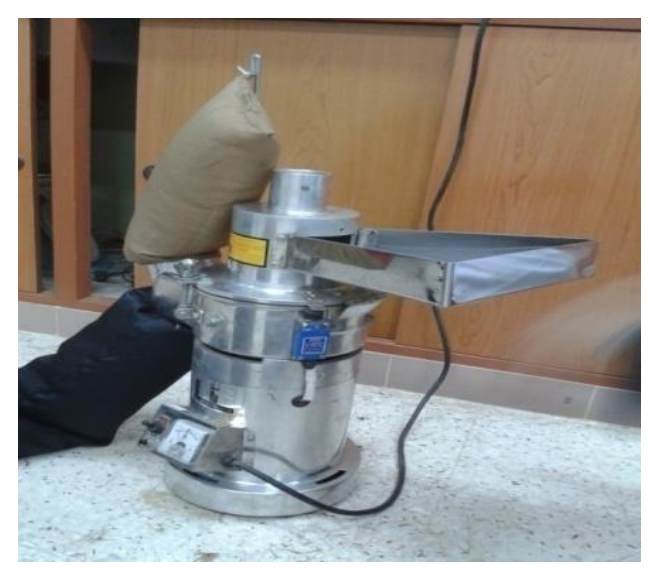

Figure 2. Shredder machine.

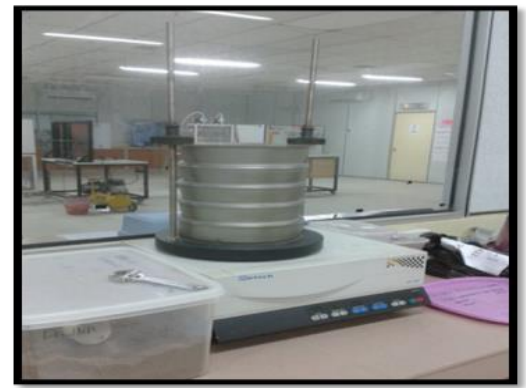

(a)

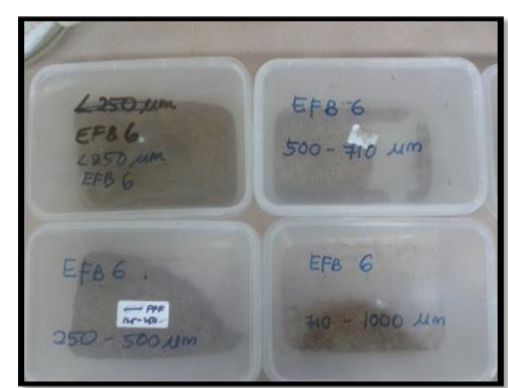

(b)

Figure 3. Sieve process: (a) sieve device; (b) EFB bunch with different sizes after sieving

The particle size of the biomass feedstock has a strong influence on the heating rate of the solid fuel. This is an important parameter which controls the rates of drying 
and primary pyrolysis and the extent to which these processes overlap during fuel decomposition. In fact, with the largest feedstock particles, lower yields of liquids were recorded. Therefore the particle size has an effect on the secondary reaction of volatiles (Omar, Idris, Yunus, Khalid, \& Aida Isma, 2011)

\section{Pyrolysis of EFB}

There are three types of pyrolysis process, as shown in Figure 4, but in this research slow pyrolysis was applied since this experiment used a feedback reactor, which was particularly suitable for this type of pyrolysis. After going through the pre-treatment step, the EFB particles underwent the pyrolysis process in the feedback reactor.

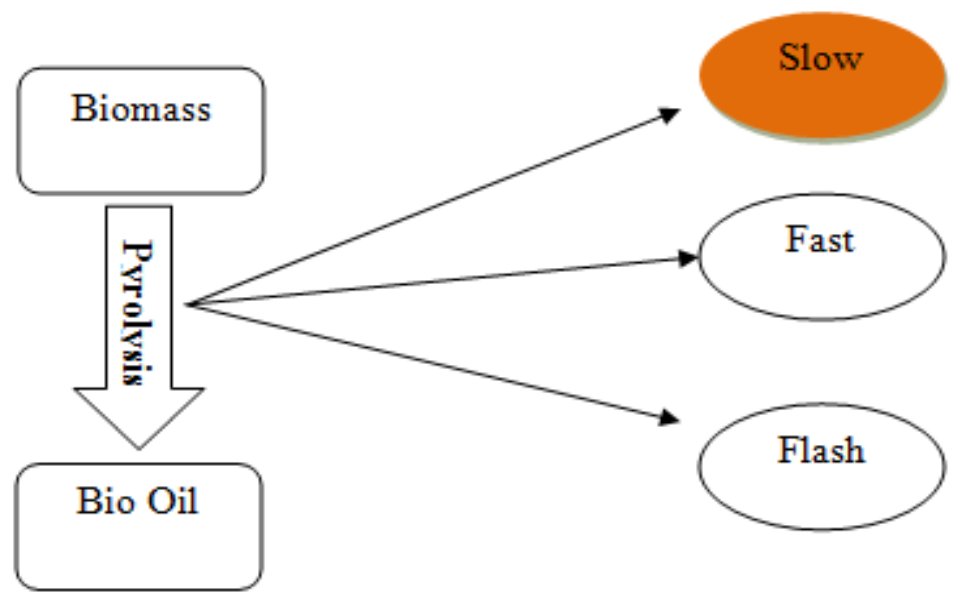

Figure 4. Types of pyrolysis.

Figure 5 shows the setup of the pyrolysis process through the schematic diagram. In this pyrolysis, the experimental rig, consisting of a semi-batch stainless steel reactor with jacketed electrical heating, was monitored by a K-type thermocouple equipped with a water-cooled product recovery system. Inert nitrogen was initially purged in the reactor for approximately 30 minutes. The pyrolysis process was operated under the optimum temperature of $300^{\circ} \mathrm{C}$ for $20 \mathrm{~min}$ at atmospheric pressure. During the reaction process, nitrogen gas was purged in the reactor to control the pressure and to avoid vapor loss. Vapor released from the reactor was cooled at a temperature of 50$60^{\circ} \mathrm{C}$; the liquid product, bio-oil, was collected in the conical flask while the noncondensable gaseous component was collected in a gas sampling bag. Figure 6 shows that a few important parts of the feedback reactor play their own role in the pyrolysis process. The furnace is an important part into which nitrogen is inserted during the process so that no oxygen will be involved in the combustion; at that time the furnace will make sure that nitrogen does not flow out during the process. The correct amounts of nitrogen are controlled with the help of the flow rate. The program controller is another significant part which controls all the pyrolysis and sets up the temperatures before the process. 


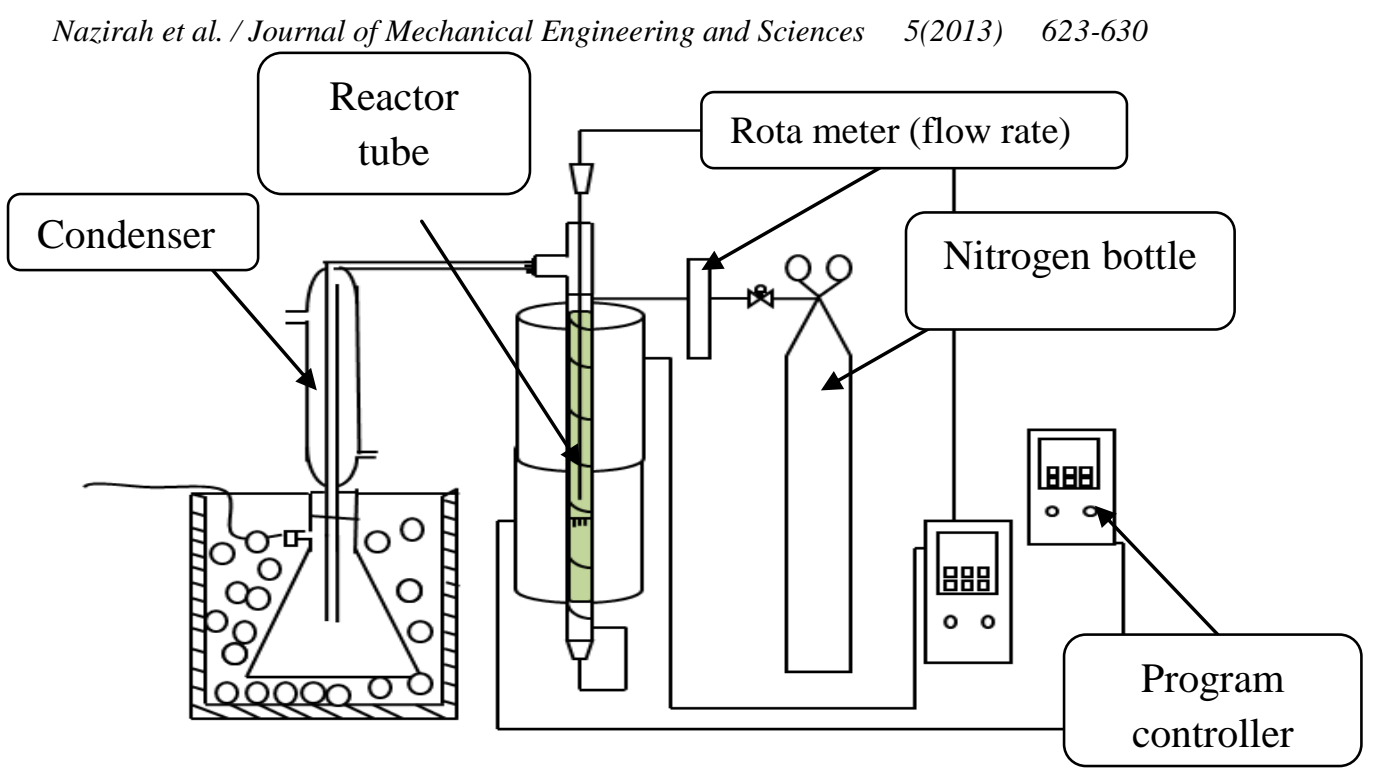

Figure 5. Schematic diagram for the pyrolysis process.

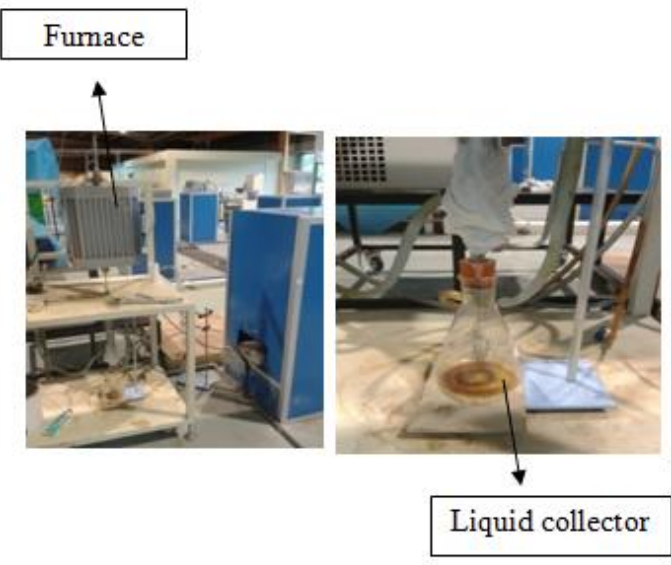

(a) (b)

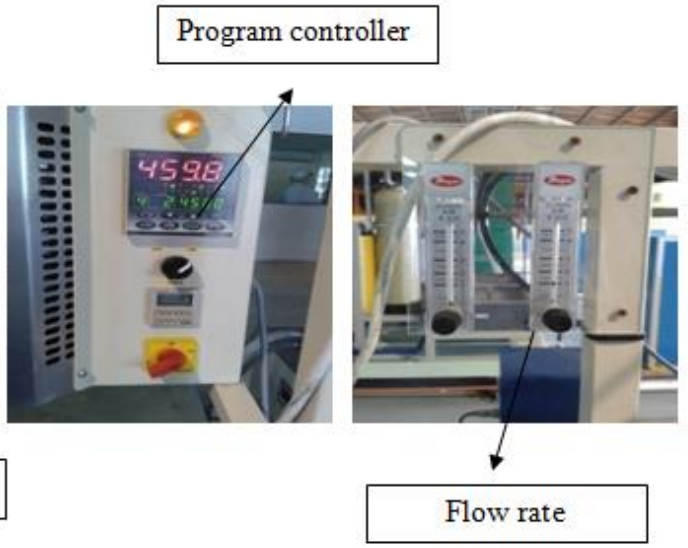

(c)

(d)

Figure 6. Parts of the feedback reactor in pyrolysis: (a) furnace; (b) liquid collector; (c) program controller; (d) flow rate

\section{Viscosity Test}

In this research, the Brookfield Viscometer was used to test the viscosity of the EFB bio-oil. The viscosity is a vital parameter that must be considered in the design or selection of handling, processing and transportation equipment. This Brookfield Viscometer measures consistency by measuring the energy needed to turn an axle in a liquid. On different models, the consistency is obtained by increasing the perusing by a consistent identified with the specific rotational velocity utilized. 


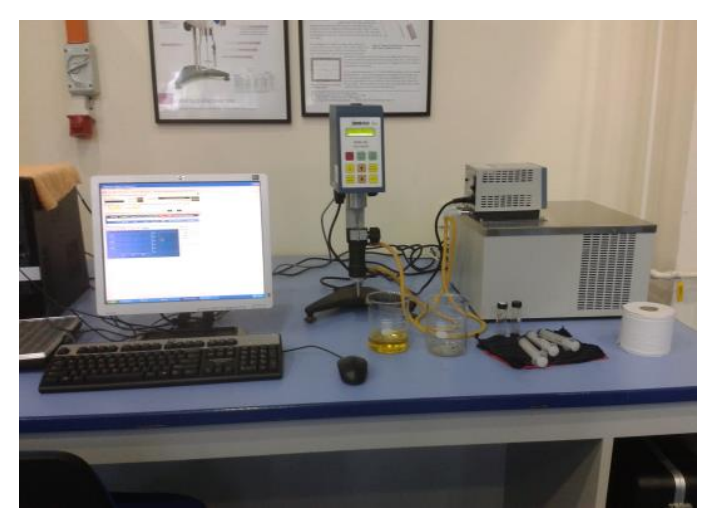

Figure 7. The Brookfield Viscometer.

\section{RESULTS AND DISCUSSION}

The viscosity of EFB bio-oils extracted from different batches of feedstock was measured at $25,30,35,40,45$, and $50^{\circ} \mathrm{C}$; tests were taken in fresh conditions and again after 24 hours of storage; this was to see if there was any change in viscosity between the two conditions. At the same time, different quantities of acetone were added to different batches of bio-oils in order to investigate the effects of chemical reactions on their viscosity. All the data and results obtained are shown in the figures below. In Figure 8 , it can be seen that the viscosity of pure EFB bio-oil decreases as the temperature increases. At the same time, after storage of the bio-oil for 24 hours, the viscosity increases at room temperature; however, it decreases successively as the temperature increases in the range of $25^{\circ} \mathrm{C}-50^{\circ} \mathrm{C}$. The highest viscosity of pure EFB bio-oil recorded in this study was $2.5322 \mathrm{mPas}$.

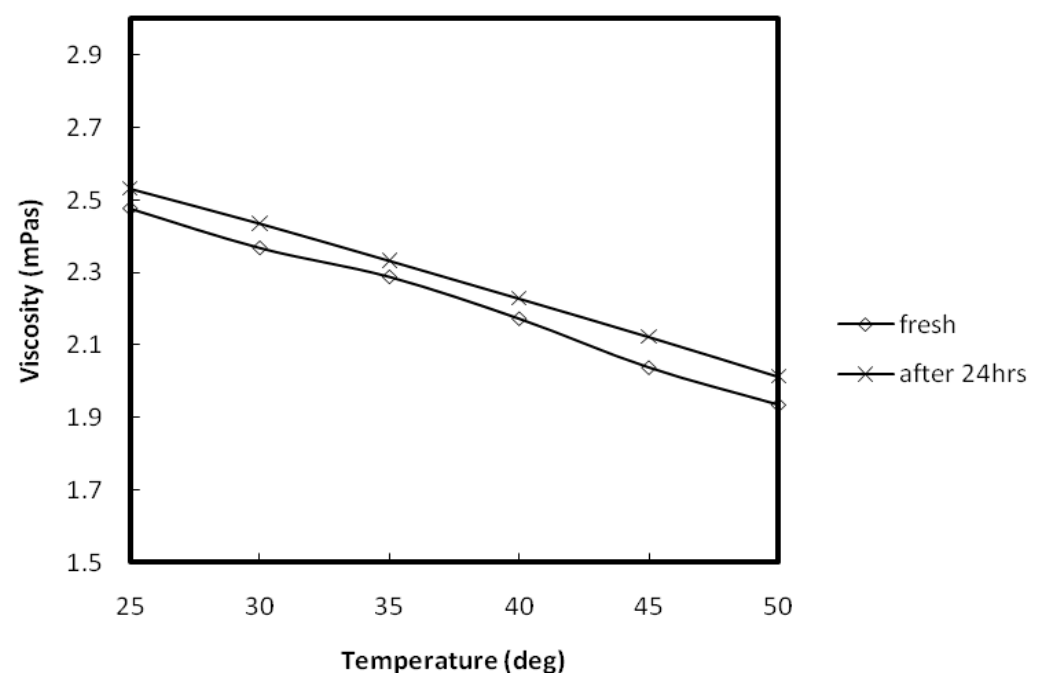

Figure 8 . The viscosity of EFB bio-oil (mPas) versus temperature $\left({ }^{\circ} \mathrm{C}\right)$ without chemical treatment.

Figure 9 shows the viscosity of EFB bio-oil versus temperature immediately after the chemical reaction with acetone. It can be seen that the highest viscosity of the bio-oil mixture is at $25^{\circ} \mathrm{C}$ when $10 \mathrm{ml}$ of acetone is added. The viscosity decreases 
slightly when the temperature is raised from $25^{\circ} \mathrm{C}$ to $30^{\circ} \mathrm{C}$; it slightly increases when the temperature is raised further to $35^{\circ} \mathrm{C}$; from this point onwards, the viscosity keeps decreasing as the temperature rises steadily until $50^{\circ} \mathrm{C}$. When $20 \mathrm{ml}$ of acetone is added to the bio-oil, the chemical reaction causes the viscosity to rise higher than the viscosity of EFB bio-oil without the chemical reaction. The highest viscosity of the bio-oil among the three conditions is the bio-oil that has the chemical reaction with the addition of 10 $\mathrm{ml}$ of acetone, which is $2.6751 \mathrm{mPas}$ at $35^{\circ} \mathrm{C}$. In Figure 10, the patterns in the graph for the viscosity of all bio-oils shows a decreasing trend when the temperature is increased from $25^{\circ} \mathrm{C}$ to $50^{\circ} \mathrm{C}$. There are no significant changes in viscosity between Figure 10 and Figure 9 under the conditions of $10 \mathrm{ml}$ and $20 \mathrm{ml}$ of acetone, even though the bio-oil was stored for 24 hours. However, the viscosity of the bio-oil that reacted with $20 \mathrm{ml}$ of acetone is very close to the viscosity of the EFB bio-oil that reacted with $10 \mathrm{ml}$ of acetone.

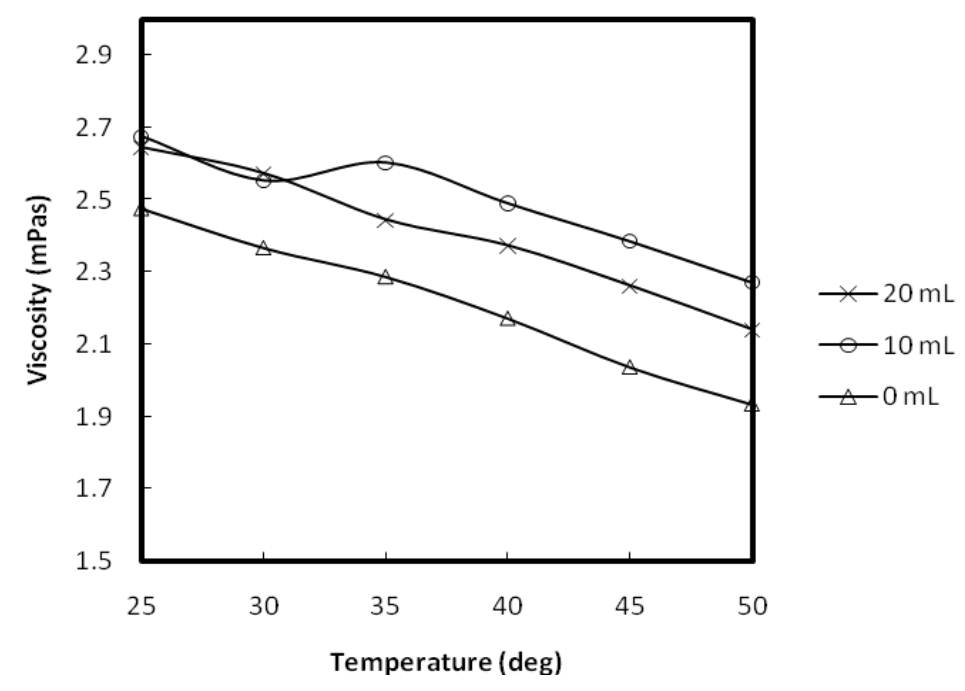

Figure 9. The viscosity of EFB bio oil (mPas) versus temperature $\left({ }^{\circ} \mathrm{C}\right)$ directly after the chemical treatment.

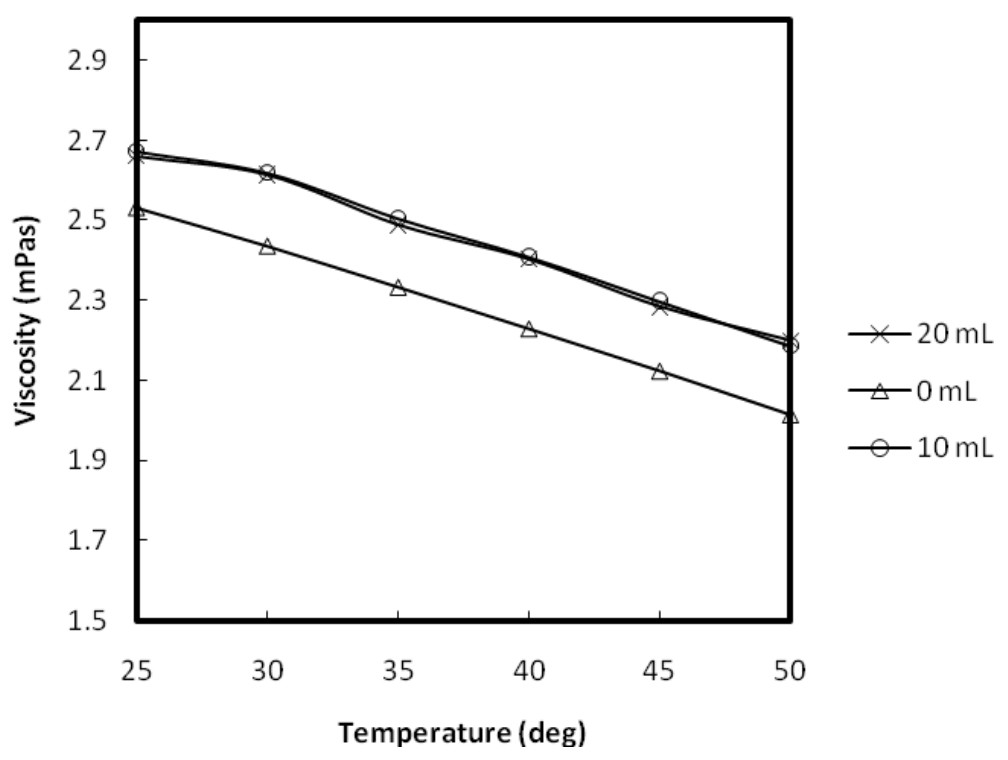

Figure 10. The viscosity of EFB bio oil (mPas) versus temperature $\left({ }^{\circ} \mathrm{C}\right) 24$ hours after the chemical treatment. 


\section{CONCLUSIONS}

Chemical pre-treatment by using acetone was found to be another method to increase the viscosity of the EFB bio-oil. In this research, a few key findings emerged from the results obtained during the experiment. Firstly, there is no significant change in viscosity between bio-oil treated immediately with the chemical and bio-oil treated with the chemical after 24 hours of storage. This indicates either that the storage time will not affect the viscosity, or that more than 24 hours are needed to see changes in the viscosity. In this research, it was shown that the presence of acetone affected the viscosity of EFB bio-oil, and in order to save cost, $10 \mathrm{ml}$ of acetone is sufficient to increase the viscosity. The experiment proved that $10 \mathrm{ml}$ of acetone gives the highest viscosity of EFB bio-oil at $35^{\circ} \mathrm{C}$. Overall, it can be concluded that the viscosity of EFB bio-oil is lower when the temperature is increasing in the range $25^{\circ} \mathrm{C}-50^{\circ} \mathrm{C}$.

\section{ACKNOWLEDGEMENTS}

The authors wish to thank the School of Mechatronics Engineering and School of Bioprocess of Universiti Malaysia Perlis for their support and cooperation in the course of this study. The authors are also grateful for Short-term Grant (STG) no. 9001-00362 and for financial support under the Ministry of Higher Education's Fundamental Research Grant Scheme (FRGS) no. 9003-00318.

\section{REFERENCES}

Abdullah, N. (2005). An assessment of pyrolysis for processing empty fruit bunches. Aston University.

Abdullah, N., \& Gerhauser, H. (2008). Bio-oil derived from empty fruit bunches. Fuel, 87(12), 2606-2613.

Gawrilow, I. (2003). Palm oil usage in lubricants. Paper presented at the Proceedings of the third global oils and fats business forum. United States of America.

Hassan, O. A., Ishida, M., Shukri, I. M., \& Tajuddin, Z. A. (1994). Oil-palm fronds as a roughage feed source for ruminants in malaysia: Malaysian Agriculture Research and Development Institute (MARDI).

Isahak, W. N. R. W., Hisham, M. W., Yarmo, M. A., \& Yun Hin, T.-y. (2012). A review on bio-oil production from biomass by using pyrolysis method. Renewable and Sustainable Energy Reviews, 16(8), 5910-5923.

Omar, R., Idris, A., Yunus, R., Khalid, K., \& Aida Isma, M. (2011). Characterization of empty fruit bunch for microwave-assisted pyrolysis. Fuel, 90(4), 1536-1544.

Syahrullail, S., Zubil, B., Azwadi, C., \& Ridzuan, M. (2011). Experimental evaluation of palm oil as lubricant in cold forward extrusion process. International journal of mechanical sciences, 53(7), 549-555.

Yiin, C. L. (2013). Stabilization of empty fruit bunch (efb) derived bio oil. from http://utpedia.utp.edu.my/8496/. 